\title{
Impact of Quarantine on Psychological and Psychosocial Aspects in Individual and Health Care Staff
}

\author{
Nitesh Malhotra ${ }^{1}$, Pooja Chaudhuri ${ }^{2}$, Aksh Chahal $^{3}$ \\ ${ }^{1}$ Assistant Professor, Amity Institute of Physiotherapy, Amity University, Uttar Pradesh, India, ${ }^{2}$ Associate \\ Professor, Department of Physiotherapy University of Science and Technology, Meghalaya, India, ${ }^{3}$ Professor, MM \\ Institute of Physiotherapy and Rehabilitation, Maharishi Markandeshwar (Deemed to be University), Ambala, \\ Haryana, India
}

\begin{abstract}
Even a thought for an outbreak of an infectious disease provokes unwarranted panic and emotional distress in population causing development of negative impacts on psychological and psychosocial parameters of an individual. So, in case of any real epidemic/pandemic outbreak the normal psychological and psychosocial parameters start getting affected gradually which rise in amplitude as time pass while the disease is in air. Immediately, starts the phase of stress and fear of either being a carrier or a healthy individual who will have to live a compromised life for a particular duration. Previous studies have shown quarantine period to grimly affect individuals along with their health care providers which can even go along for the coming years. These impacts if controlled by early execution of strategies through governmental, administrative and social bodies working resourcefully and effectively can reduce the distress before being amplified. The present paper outlines the negative impacts of quarantine on psychological and psychosocial domain in individuals put in quarantine along with health staff engaged in their treatment. In addition, the article also narrates and suggests recommendations after reviewing articles from reputed database published following the outbreak of Severe Acute Respiratory Syndrome (SARS), Ebola Virus Disease (EVD) and Middle East Respiratory Syndrome Corona Virus (MERS CoV) with added suggestions in reducing the effects during and after quarantine.
\end{abstract}

Keywords: Quarantine, Isolation, Negative, Psychological, Psychosocial, Health, COVID-19.

\section{Introduction}

'Quarantine' is a public health measure characterized by separation and restriction in movement of individuals' who are assumed to be exposed to a contagious disease, to confirm if they become unwell so as to reduce the risk of spreading the same to the healthy population ${ }^{1,2}$. Quarantine is similar to Isolation but not the same. 'Isolation' is defined as separation of patients diagnosed

\footnotetext{
Corresponding Author:

Aksh Chahal

Professor, MM Institute of Physiotherapy and

Rehabilitation, Maharishi Markandeshwar (Deemed to

be University), Ambala, Haryana, India

e-mail: drakshchahal@gmail.com
}

with a contagious disease from population who are not $\operatorname{sick}^{(3,4)}$. The well-known example of isolation is of Human Immunodeficiency Virus (HIV) positive patients in Cuba during the 80's and 90's ${ }^{(4,5)}$. Generally, both these terminologies are used as synonyms to each other but in fact, they differ in the categorization of patients from normal healthy population. Looking back in history, the term quarantine was used for the first time in $1127 \mathrm{AD}$ in Venice, Italy following the outbreak of Leprosy which nearly wiped their major population ${ }^{2}$. The same term was used after 300 years with an outbreak of Plague in United Kingdom, killing large number of people and health care workers ${ }^{(6)}$. Since then, the term has been used couple of times following outbreak of Ebola Virus Disease (EVD) during 2005 originating in Congo, West Africa ${ }^{7}$, Severe Acute Respiratory Syndrome (SARS) during 2003 originating in Toronto 
(Canada $^{(8,1,4)}$, Middle East Respiratory Syndrome Corona Virus (MERS-CoV)in Korea during 2015(9) and now, its Corona Virus named 'COVID-19' starting from Wuhan, a city in China in 2019 which rapidly spread to other nations ${ }^{(2)}$. As an immediate response, the city of Wuhan was lockdown and the suspected individuals put to quarantine irrespective of their gender and age. In a short span, even nearby cities and major cities of China were put to lockdown with strategies following as exhibited in Wuhanfor months to come while the remaining population was either asked to be contained at home or embossed at their present site till further communications $^{(2)}$.This sudden outbreak left both, the people in quarantine and lockdown in a nowhere to go situation, firstly due to lack in awareness of the virus being spread and whether they themselves are affected by the virus and if they are affected, concern regarding their self, families, future, issues in association with social stigma $(4,10)$, fulfillment of daily, personal and financial needs ${ }^{(11,12,13)}$. These thoughts start dominating an individual's psychology creating negative engravings towards short and long term goals and propositions of life. The affected individual are put in quarantine while the unaffected to a lockdown wherein people still share and exhibit advantage than people in quarantine as they spend time with their family and loved ones, peruse studies if students, control financial balance by working from home, eat food of their choice etc. In the present article, the author would concentrate specifically on the negative impacts of quarantine. To achieve this goal, the impacts shall be documented as; negative impacts experienced by individuals admitted in quarantine and on health care providers working in the quarantine facilities. After searching articles from premier database and analyzing the articles in depth the author has simplified and grouped the impacts for ease of readers,

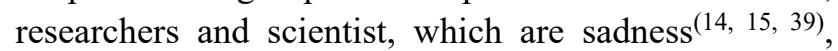
confusion $^{(15,16,17,39)}$, numbness ${ }^{(15)}$, low $\operatorname{mood}^{(12,18,39)}$,

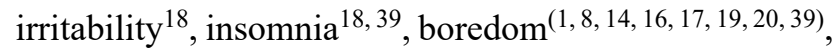
$\operatorname{anger}^{(14,16,21)}$, nervousness $^{(15)}$, depression $^{(1)}$, anxiety ${ }^{(20)}$, fear of infection ${ }^{(16,20,23)}$ and infecting others $(4,8,16,20$, 24), emotional disturbance ${ }^{1,8}, 14$, exhaustion ${ }^{(10,14,25)}$, PostTraumatic Stress Syndrome (PTSS) ${ }^{(1,4)}$ and at times thinking of committing suicide ${ }^{(26)}$.In contrast, negative impacts through which heath care providers mainly suffer are irritability ${ }^{24}$, anxiety $(24,37)$, insomnia ${ }^{(24)}$, exhaustion $^{(24)}$, angry ${ }^{(8)}$, poor-concentration leading to indecisiveness $^{(24)}$ and reluctance to work $^{(24)}$, emotional stress $(14,27,28,29,31)$, High Depressive Symptoms(HDS) ${ }^{(30)}$, loss of intimacy $(8,37)$, fear of $\operatorname{stigma}^{(8,37)}, \operatorname{PTSS}(1,4$,
29) and detachment from family $(24,37,38)$, relatives $(24,38)$ and neighbors $(4,8,15,23,24,37,38)$.

All the above impacts are not necessarily seen in all individuals and health workers.According to previous researches not all are seen at same instinct of time, rather few impacts are seen in the beginning of quarantine, followed by during middle and the seriously impactful through the long stay or end days being quarantined. There can be single or combination of impacts which depend on the pre-psychological wellbeing ${ }^{(1,4)}$, duration of quarantine the individual is asked to stay ${ }^{(1)}$, self-mindset ${ }^{(1,4)}$, acceptance and level of determination to overcome the current situation $(1,4)$ and guidance and support provided by health care staff and psychiatrist ${ }^{9}$. Individuals with abalanced financial background feel readily comfortable when compared with underprivileged ones ${ }^{(2)}$.

\section{Strategies to mitigate consequences of quarantine:}

1. Swift action to shrink emotional, psychological and social negative picture in aperson promoting a normal psychological approach towards the existing temporary situation from professional Psychiatrist. Role of Psychiatrist have been proved to be vital in researches during quarantine following previous outbreaks ${ }^{(9)}$.

2. Availability of reliable, rational and uncomplicated information from governmental and public health departments involved directly in action or working in combination with the main agencies for recent intervention being implemented, along with future projections to be implied if required should be broadcasted on regular basis for betterment of even the underprivileged section of population ${ }^{(32)}$.

3. Dietary and sleep schedule, similar as that of prior to outbreak of Quarantine, should be followed as these unswervingly have an effect on mental Health.

4. Individuals can be kept occupied by endorsing them in their respective hobbies, choice thus preventing growth of even tiny negative impact on mental wellbeing.

5. A positive approach of helping others to conquer similar situation amongst family associates and populace in contact through social media promote ability to be occupied and accepting the condition and possibly looking for ways to eradicate the same ${ }^{(11,15,34)}$. 
6. Assurance of a regular supply of daily needs for subjects in quarantine to individuals from underprivileged sections reduces risk for development of negative impact ${ }^{(3)}$.

7. In today's world, mobile is a necessity than luxury. It has proved its metal to be efficient in slowing the creation of negative impacts even during long stays during quarantine as the individual are occupied by exploring their interest, exchanging views via social networking websites and coming across developments across the world ${ }^{(3,33)}$.

8. Government should initiate free online, broadcasting counseling programs via television and radio to minimize the figure of people being engraved amid negativeimpacts ${ }^{(34)}$.

9. Special focus to be paid on health staff working during quarantine by administrative and agencies delivering and monitoring services ${ }^{(35,36)}$.

10. Prioritization of steps taken to balance professional, psychological, personal and social attributes for staff engaged with quarantine subjects ${ }^{(35)}$ by benefitting from comfortable working hours in shifts, remuneration and perks apart from regular salaries should be constituted.

\section{Conclusion}

The phase of quarantine produces negative impacts on one's psychological and psychosocial aspects of life. Some individuals present with few, while mostly demonstrate multiple negative impacts making the situation concernable bringing in interventions even from other domains of health care, example Psychiatry. Majority of individual kept in quarantine facilities present with sadness due to detachment from family, relatives and fear and concerns regarding upcoming future rejections from neighbors', social setups. Anger towards inability to balance personal, daily and financial needs summate addition of other effects bulging the balloon of negative impacts. Even the health care providers experience the same issue of neglect from family, relatives and neighbors as they are thought to bring in infection from the quarantine facilities. Health worker friendly policies should be instituted from governmental agencies to minimize the exposure time for health workers, providence of duty off on regular intervals, extra remuneration. All health workers work in quarantine facilities with dedication without stepping back to impart best available treatments serving
mankind.It should be brought to think that these health care workers too are humans and experience similar views as they are the one exposed to the pandemic or epidemic disease as the first shield of prevention of spread of the disease.

\section{Conflict of Interest: NIL}

\section{Source of Funding: NIL}

Ethical Clearance: Not applicable

\section{References}

1. Hawryluck L et al .SARS Control and Psychological Effects of Quarantine, Toronto, Canada.Emerging Infectious Diseases. 2004; 10(7):1206-1212.

2. Brooks SK, et al. The psychological impact of quarantine and how to reduce it:rapid review of the evidence. The Lancet. 2020;395:912-920.

3. Manuell M-E, et al. Mother Nature versus human nature: public compliance with evacuation and quarantine. Disasters. 2011; 35:417-442.

4. Reynolds DLet al. Understanding, compliance and psychological impact of the SARS quarantine experience. Epidemiol. Infect. 2008; 136: 9971007.

5. Hansen Het al. Human immunodeficiency virus and quarantine in Cuba. Journal of the American Medical Association. 2003;290:2875.

6. Newman K. Shutt up: bubonic plague and quarantine in early modern England. J Sol Hist. 2012;45:809-834.

7. Hasan Set al. Ebola virus: A global public health menace: A narrative review. J Family Med Prim Care. 2019; 87: 2189-2201.

8. Robertson Eet al. The psychosocial Effects of Being Quarantined Following Exposure to SARS: A Qualitative Study of Toronto Health Care Workers. Can J Psychiatry. 2004; 49(6): 403-407.

9. Lee SMet al. Psychological impact of the 2015 MERS outbreak on hospital workers and quarantined hemodialysis patients. Comprehensive Psychiatry. 2018;87:123-127.

10. Tansey CMet al. One-year outcomes and health care utilization in survivors of Severe Acute Respiratory Syndrome. Arch Intern Med. 2007; 167:1312-20.

11. Jeong $\mathrm{H}$, et al. Mental health status of people isolated due to Middle East Respiratory Syndrome. Epidemiol Health. 2016;38:e2016048. 
12. Taylor MRet al. Factors influencing psychological distress during a diseases epidemic: data from Australia's first outbreak of equine influenza. BMC.Public Health. 2008;8:347.

13. Mihashi Met al. Predictivefactors of psychological disorder development duringrecovery following SARS outbreak. Health Psychol. 2009;28:91-100.

14. Maunder Ret al. The immediate psychological and occupational impact of the 2003 SARS outbreak in a teaching hospital. Can Med Assoc. 2003; 168:1245-51.

15. Pan PJDet al. A support group for home quarantined college students exposed to SARS: learning from practice. J Spec Group Work. 2005;30:363-74.

16. Cava MAet al. The experience of quarantine for individuals affected by SARS in Toronto. Public Health Nurs. 2005;22:398-406.

17. Braunack MAet al. Understanding the school community's response to school closures during the H1N1 2009 influenza pandemic. BMC. Public Health.2013; 13:344.

18. Lee Set al. The experience of SARS-related stigma at Amoy Gardens. SocSci Med. 2005;61:2038-46.

19. Yoon MKet al. System effectiveness of detection, brief intervention and refer to treatment for the people with post-traumatic emotional distress by MERS: A casereport of community based proactive intervention in South Korea.Int J Ment Health Syst. 2016;10:51.

20. Desclaux Aet al. Accepted monitoring or endured quarantine. Ebola contacts' perceptions in Senegal. SocSci Med. 2017; 178:38-45.

21. Marjanovic Zet al. The relevance of psychosocial variables and working conditions in predicting nurses' coping strategies during the SARS crises: an online questionnaire survey. Int J Nurs Stud. 2007; 44:991-98.

22. DiGiovanni Cet al.Factors influencing compliance with quarantine in Toronto during the 2003 SARS outbreak. Biosecur Bioterror. 2004; 2: 265-72.

23. Pellecchia Uet al. Social consequences of Ebola containment measures in Liberia. PLoS One. 2015; 10: e0143036.

24. Bai Yet al. Surveys of stress reactions among health care workers involved with the SARS outbreak. Psychiatr Serv. 2004;55:1055-57.

25. Sprang Get al. Post traumatic stress disorder in parents and youth after heath-related disasters. Disaster Med Public Health Prep. 2013;7:105-10.

26. Barbisch Det al. Is there a case of quarantine? Perspectives from SARS to Ebola. Disaster Med Public Health Prep. 2015;9:547-53.

27. Lancee WJet al. Prevalence of psychiatric disorders among Toronto hospital workers one to two years after SARS outbreak. Psychiatr Serv. 2008;59(1):91-5.

28. Hong Xet al. Post traumatic disorder in convalescent sever acute respiratory syndrome patients: a 4 year follow-up study. Gen Hosp Psychiatry. 2009; 31(6): 546-54.

29. Mak JWet al. Long-term psychiatric morbidities among SARS survivors. Gen Hosp Psychiatry. 2009; 314: 318-26.

30. Liu Xet al. Depression after exposure to stressful events: Lessons learned from the severe acute respiratory syndrome epidemic. Compr Psychiatry. 2012; 53: 15-23.

31. Wester Met al. Ebola and healthcare worker stigma. Scand J Public Health. 2019; 47: 99-104.

32. Brahmbhatt Met al. On SARS type economic effects during infection disease outbreaks. The World Bank, East Asia and Pacific Region, Policy Research Working Paper. 2008: 4466.

33. Rubin GJet al. Psychological and behavioral reactions to the bombings in London on 7 July 2005:a cross sectional survey of a representative sample of Londoners'. BMJ. 2005;331:606.

34. Johal SS. Psychosocial impacts of quarantine during disease outbreaks and interventions that may help to relieve strain. New Zealand Medical Journal. 2009;122 (1296): 53-58.

35. Rubin GJet al. How to support staff deploying on overseas humanitarian work:a qualitative analysis of responder views about the 2014/15 West African Ebola Outbreak. Eur J Psychotraumatol. 2016;7:30933.

36. Wu Pet al. The psychological impact of the SARS epidemic on hospital employees on China: exposure: risk perception and altruisticacceptance of risk. Can J psychiatry. 2009;54:302-11.

37. Chan AOet al. Psychological impact of the 2003 severe acute respiratory syndrome outbreak on health care workers in a medium size regional general hospital in Singapore. Occup Med. 2004;54(3):190-6. 
38. Nickell LAet al. Psychosocial effects of SARS on hospital staff: survey of a large tertiary care institution. CMAJ.2004.170 (5): 793-8.
39. Leung GMet al. A tale of two cities: Community psychobehavioural surveillance and related impact on outbreak control in Hon Kong and Singapore during the severe acute respiratory syndrome epidemic. Infect Control Hospital Epidemiol. 2004; 25: 1033-41. 